\title{
Tarihsel ve Coğrafi Açıdan Tekirdağ ve Çevresi: Kent, Külltür ve Kimlik
}

Dimitris A. Mavridis, İstanbul'dan Tekirdağ'a, Çă̆daş Yunan Kimliğinin Arayışında (Yunanca Aslından Çeviren: İbrahim Kelağa Ahmet), Süleymanpaşa Belediyesi Yayınları, Tekirdağ 2017, 254 sayfa, ISBN: 978-605-9386-20-3.

\section{Esin OZANSOY ${ }^{1}$ (D)}

'Prof. Dr., Istanbul University, Faculty of Letters, Department of Modern Greek Language and Literature, Istanbul, Turkey ORCID: E.O. 0000-0002-3977-7314

\section{Corresponding author:}

Esin OZANSOY, İstanbul Üniversitesi, Edebiyat Fakültesi, Batı Dilleri ve Edebiyatları Bölümü, Çağdaş Yunan Dili ve Edebiyatı Anabilim Dalı, İstanbul, Türkiye E-mail: esinozansoy@hotmail.com

Submitted: $13.05 .2019 \cdot$ Accepted: 28.05 .2019

Citation: Ozansoy, E. (2019). Tarihsel ve coğrafi açıdan Tekirdağ ve çevresi: Kent, kültür ve kimlik [D. A. Mavridis tarafından yayına hazırlanan İstanbul'dan Tekirdağ'a, Çağdaş Yunan kimliğinin arayışında (i. K. Ahmet, Çev.) başlıklı kitabın değerlendirmesi]. Litera, 29(1), $119-126$. https://doi.org/10.26650/LITERA2019-0022

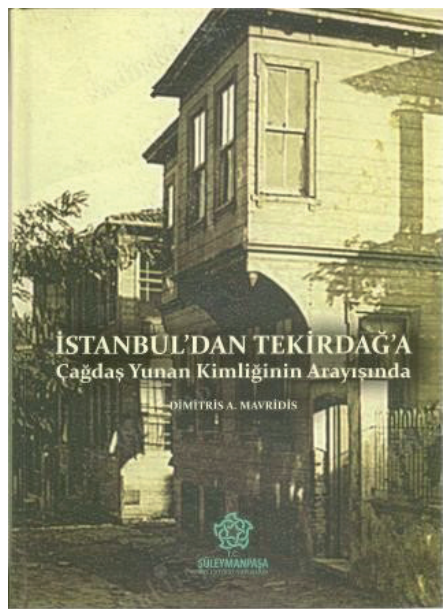

Dimitris A. Mavridis'in Istanbul'dan Tekirdağ'a Çağdaş Yunan Kimliğinin Arayışında adlı eserinin Türkçe çevirisi Tekirdağ Süleymanpaşa Belediyesi kültür yayınlarından çıkmıştır. Kitapta 48 fotoğraf, Tekirdağ'ın tarihi ahşap evlerine ait 18 çizim ve yazarın bizzat hazırladığı 3 haritadan oluşan görsel ögeler de yer almaktadır.

Bir yönüyle kent tarihi araştırması olarak da nitelendirebilecek olan kitapta, Tekirdağ kent merkezi ve bölgedeki diğer yerleşimlere ilişkin tarihi ve sosyolojik bilgiler ve yazarın gezi notları önemli 
bir yer tutmaktadır. Eserde, İstanbul ve İstanbul'un Yunanlar için tarih boyunca taşıdığı önem, Yunan kimliği, Yunanistan'ın Batı dünyası ile ilişkileri, Türkiye ve Türklere ilişkin dikkat çekici analizlere de yer verilmektedir.

Mühendis kimliği ile öne çıkan ve daha önce Türkçeye çevrilmiş herhangi bir eseri bulunmayan yazar hakkında kısa bazı bilgileri paylaşmakta yarar var. Dimitris A. Mavridis, 1942 yılında kuzey Yunanistan'ın Florina kentinde doğmuş ve Tekirdağ'dan 1922 yılında Yunanistan'a muhacir olarak göç etmiş bir aileye mensuptur. Özgeçmiş bilgilerinden başarılı bir mühendislik kariyerine sahip olduğu anlaşılan yazar, çalıştığı şirketlerin iş bağlantıları nedeniyle çoğu Yakın Doğu'ya olmak üzere dört kıtada iki yüzden fazla seyahat gerçekleştirmiştir. 1978 yılında ilgi alanını Doğu'ya yönelterek Helenistik Doğu ve Yunan ordusunun Küçük Asya (Anadolu) Harekâtına dair bir fotoğraf arşivi oluşturmuştur. Tanıtımını yaptığımız 2003 yılında yayımlanmış kitabı aslında, Doğu'daki Rum varlığı ile ilgili araştırmalarının bir ürünüdür. O tarihten beri, çoğu Kuzey Yunanistan ve özellikle (Doğu ve Batı) Trakya kentlerini konu alan on kitap ve çok sayıda makale yayımlamış, aynı konularda Yunanistan ve Ingiltere'de konferanslar vermiştir. Yazarın farklı konularda 150'nin üzerinde yazısının yer aldığı bir blogu' bulunmaktadır. Yunan ordusunun Küçük Asya (Anadolu) Harekâtı (1919-1922) ile ilgili döneme ait çok dikkat çekici 1000 fotoğrafın yer aldığı bir başka blogu² ise tarihe ilgi duyan Türk okurların mutlaka ilgisini çekecektir. Yazarın güçlü kalemi ve sahip olduğu entelektüel derinlik tanıtımını yaptığımız kitapta gözden kaçmamaktadır. Mavridis, çalışmalarından dolayı farklı kurumlardan aldığı ödüllerin yanı sıra, Trakya Demokritos Üniversitesi, Edebiyat ve Toplum Bilimleri Fakültesi, Tarih ve Etnoloji Bölümü tarafından 2017 yılında fahri doktora unvanı ile de onurlandırılmıştır.

Istanbul'dan Tekirdağ'a Çağdaş Yunan Kimliğinin Arayışında adlı eser: içindekiler, önsöz ve dört ana bölüm ile iki ek bölüm, son söz ve savunma başlıklı bir alt bölüm, bir kronolojik tablo; kaynaklar, atıflar, yorumlar alt bölümü ve kaynakçadan oluşmaktadır.

Kitabın giriş kısmında "Bir toprağa sarılmak..." (s. 13) başlığı altında Süleymanpaşa Belediye Başkanı M. Ekrem Eşkinat'tan, kapakta yer alan evin ilginç hikâyesini öğrenmekteyiz. Ev yazar Mavridis'in baba ocağıdır, ailesi 1922 göçüyle Tekirdağ'dan ayrılır ve Eşkinat'ın Selanik'ten mübadeleyle gelen ailesi Mavridis'lerin evine

1 www.mavridisdim.blogspot.com

2 www.mikrasiatikiekstratia.blogspot.com 
yerleştirilir. Eşkinat, Tekirdağ fotoğraflarını araştıııken rastladığı o evin fotoğrafının altındaki imzadan yazara ulaşır.

Ev, kamulaştııımasının ardından restore edilerek Eski Tekirdağ Fotoğrafları Müzesi'ne dönüştürülür ve yazar da Tekirdağ ile ilgili fotoğraf arşivini müzeye bağışlayarak açılış onun da katııımıyla 1 Aralık 2018 tarihinde gerçekleştirilir.

Yazar Dimitris A. Mavridis önsözde (s. 15), günümüzde Tekirdağ merkezde Ertuğrul Mahallesi sınırları içinde olduğu tespit edilen "Mnimatakia" (Mezarlık) mevkiine yaptığı bir ziyaretin, kitabın yazımına vesile olduğunu okuyucularıyla paylaştıktan sonra kitabın sıradan bir fotoğraf koleksiyonu ve seyahatleri sırasında edindiği izlenimler olarak başladığını belirtmektedir. Yazar, eserinde sadece yer, mekân, tarih, kişiler ve olguları ayrıntılı bir şekilde araştırmakla yetinmediğini, bunların ifade ettiği manaları da ortaya koyma çabası içinde olduğunun altını çizerek kitapta yazdıklarının Yunan merkezli bir bakış açısına dayandığını özellikle vurgulamaktadır.

Yazar, Türkçe çeviri için kaleme aldığı önsözde (s. 21) kitabın çevirisinin yazımından 15 yıl sonra gerçekleştiğini ve çeviri için yapılan düzenlemelerde Yunan/Rum unsuru ile ilgili betimlemelere ve konulara ağırlık verildiğini kaydetmektedir. Kitabın iç kapak kısmında yer alan çevirmenin notundan yazarın Türk okurunun ilgi ve hassasiyetlerini gözeterek kaynak kitapta değişiklikler yaptığını ve okurun ilgisini çekmeyeceğini düşündüğü bazı bölümleri çıkardığını öğrenmekteyiz. Kitapta yer alan eski fotoğraflar yazarın koleksiyonundan sağlanmış, güncel olanlar ise çeşitli tarihlerdeki Türkiye ziyaretleri sırasında kendisi tarafından çekilmiştir.

Kitabın birinci bölümü "İstanbul'un Dışında ve Marmara'nın Trakya Kıyısında" (s. 25-34) başlığını taşımaktadır. Yazar "İstanbul'un Kentsel Kabusu, Kültürlerin Kriz Belirtisi Olarak Kozmo (Mega) Kent" alt başlığı altında bir mega- kent olarak İstanbul'un yayıldığı geniş alan ile Marmara kıyısı boyunca devam eden yoğun yapılaşmaya, estetik yoksunluğuna ve bölgenin nüfus oranındaki artışa dikkat çekmektedir. İstanbul'un iç göç sonucu aşıı derecede kalabalıklaşması ve kentin kültürel dokusuyla uyum sağlamada zorlanan sakinlerinden söz ederken benzer durumun dünyadaki tüm mega kentlerde de yaşandığını ancak İstanbul'un hayranlık uyandıran anıtlarıyla eşsiz güzelliğini ve tarihi yarımadadaki imparatorluk metropolü havasını muhafaza ettiğini kabul etmektedir. Yazar mega kentlerin sermayenin karşı konulmaz gücünün bir tezahürü olduğunu ve bu tarz kentlerin egemen olmasıyla 
"seçkin toplumun" bir metaya dönüşerek insanın çevresine karşı yabancılaştığı tespitinde bulunmaktadır. Birinci bölümde Silivri ve Marmara Ereğlisi'yle ilgili olarak bu yerleşimlerin tarihsel geçmişlerine göndermede bulunan gözlemlerine de yer vermektedir. Bu bölümde yazarın hazırladığı iki harita da bulunmaktadır. 28. ve 29. sayfalarda yer alan, Marmara Denizinin Trakya kıyısını gösteren birinci haritada 1922 öncesi Rum nüfus barındıran yerleşim birimleri görülmektedir. Haritada Türkçeleştirme yapılmamıştır ve yer adları Yunanca yazılıdır. 32. sayfada yer alan ve Tekirdağ'ın 1922 öncesine ait Rum ve diğer gayrimüslim mahalleleriyle önemli yapılarının lokalize edildiği harita kent tarihi açısından önem taşımaktadır.

Tekirdağ (s. 35-56) başlığını taşıyan ikinci bölümde yazar, "Tekirdağ (Redestos) Sonsuza Kadar Yitik Bir Kent", "Tekirdağ Ahşap Evlerden Oluşan Bir Kent", "Osmanlı Ahşap Evi" alt başlıklarında kent tarihine ışık tutmakta ve Osmanlı dönemi kentlerindeki ahşap evler hakkında ilginç ayrıntılar vermektedir. Yazar burada bölüm başlı̆̆ılla çok uyumlu olmayan konulara da değinmektedir. Bunlar, "Türkiye'nin Batılılaşma Utkusu", "Türk Iyimserliği ve Yunan Karamsarlığı", "Türkiye'nin Üç Kesimi", "Avrupa Üzerinde İki Kültür" şeklinde sıralanabilir. Türkiye'nin Batılılaşma yönünde attığı adımlar yazarın önemli bulduğu konulardan biridir, "Türkiye'nin Avrupa Birliğine girişi, Türklerin Orta Asya'daki ata yurtlarından çıkışlarının ve Batı'ya olan yolculuklarının varış noktası olacaktır" (s. 49) ifadesi bu konudaki görüşünü yansıtmaktadır.

"Ganos (Işıklar) Dağı" (s. 59-69) başlıklı üçüncü bölümde, Ganos Dağı'nın coğrafyasından ve bu bölgede yer alan "Işıklar” (Sholario), "Uçmakdere" (Avdimio) gibi bazı yerleşim birimlerinin tarihinden söz edilmektedir. Bu bölümde de yazar "Türk Yunan Meseleleri", "Günümüzde Türkiye'de İslam", "Atatürk", "Yunanistan: Büyük Ülküleri Olan Küçük Bir Ülke" gibi alt başlıklarda değişik konuları da ele almaktadır. Burada yazar, Tekirdağ bölgesindeki seyahatleri sırasında vatandaşlarla yaptığı sohbetlerden edindiği izlenimlere dayanarak değerlendirmelerde bulunmaktadır. Dikkat çekici bazı tespitleri şöyledir:

...Türkiye köklü değişimlerin çok kısa süre içinde gerçekleşebileceği bir ülke. Koşullara uyum sağlamak bu ülkenin hoşuna gitmektedir, değişmek isteyen bir ülke. Bu, Türklerin yabancısı oldukları çevrelerde hayatta kalmayı başarma konusundaki yeteneklerinin en karakteristik görünümlerinden biridir. Aşırı derecede rekabetçi bir küresel ekonomik 
ortamda Türkiye'nin modern sanayi üretimi anlayışına çok hızı ıir şekilde adapte olması gerçekten şaşırtıcıdır. Biz bunu başaramadık. (s. 67)

Mavridis'in Atatürk'le ilgili eleştirel yönü de olan değerlendirmesi şöyledir:

Atatürk'ün çelikten kararlılığına, cesaretine, liderlik konusundaki üstünlüğüne, hayret uyandıran vazgeçilmezliğine, Türklük bilincinin oluşmasındaki başarısına, birbiriyle harmanlayarak vatanının hizmetine sunduğu hümanizm ve sertliğe hayranlık duyuyorum. Ancak, onun eseri dışında, bizi ilgilendiren kısmıla ilgili olarak Türkleri zor kullanarak Avrupalılaştırma ve bu yolla Batı tarzı bir ulus devleti oluşturma çabasını kabullenemem. (s. 68)

Yazar, yaşlı bir Türk vatandaşıyla yaptığı sohbette Yunanistan için yapılan "Büyük ülküleri olan küçük bir ülke" yorumundan hareketle Türkiye'de sıklıkla küçük Yunanistan'a yapılan göndermeyi kibirli bir tutum olarak gördüğünü belirterek bundan duyduğu rahatsızlığı dile getirmektedir. Ona göre:

Küçük Yunanistan'a atıfta bulunma, imparatorluk geçmişine gönderme yapan ve Türkiye Cumhuriyeti'ni Osmanlı İmparatorluğu'na bağlayan, Türkiye'nin büyüklüğüne ve imkânlarına yönelik bir anlayışı da ima ediyor. Bu anlayış, demografik büyüklükler ve askeri potansiyele, jeopolitik planlamalara, bölgesel güç olarak Türkiye'nin geleceğine ve "21.yüzyılın Türklerin yüzyılı olması için" Türklüğün zaferine ilişkin modern Türkiye'nin iddialı planlamalarının sorumlusudur. Bu anlayış, Türk milliyetçiliğinin ideolojisinin özelliğini oluşturmaktadır ve sadece Türkiye için değil, Yunanistan için de tehlikelidir. (s. 69)

"Ganohora" (s. 71-84) başlığını taşıyan dördüncü bölümde, "Ganohora Sahili" alt başlığı altında 1922 öncesinde ağılıklı olarak Rum nüfusun yaşadığı, adını birbirine komşu iki kasaba olan Ganos (Gaziköy) ile Hora'dan (Hoşköy) alan bölgedeki köy ve kasabalar tanıtılmakta ve bölge Rumlarının kültürlü, dindar ve çalışkan oluşlarına vurgu yapılmaktadır.

"Gaziköy (Ganos)", "Ganos'un İç Kalesi", "Şarköy (Peristasi)" bu bölümde coğrafi ve tarihi özellikleriyle tanıtılan yerleşimlerdir. Yazar bu bölümde "Rum mu Yunan mı? 
Çağdaş Yunan Kimliği İçin Ifşa Edici Bir Deneyim" alt başlığı altında kimlik konularına girmekte ve "Rum" ile "Yunan" kavramlarının Türkiye'de ve Yunanistan'da nasıl algılandığını kendi bakış açısıyla açıklamaktadır. Yazara göre:

...Türkler için "Rum" halefi olmak istedikleri Osmanlı İmparatorluğu ile bağlantılıdır. "Rum" Türklerin bizzat kendilerinin hayatta kalmasına izin verdikleri ve bu nedenle onlara minnet borcu olan "reayadır". Oysa Yunan, yabancı, küçük bir Batı ülkesinin vatandaşıdır." (s. 79)

"Yunanistan'da "Rum" adlandırması bir ölçüde bariz olumsuz bir anlam taşımaktadır, ikiyüzlü bir alçakgönüllülük, hilekârlık ve zavallııı ima eder ve özellikle de Türklerle Yunanların acı tatlı birlikte yaşadığı hazin dönemleri anımsatmaktadır. (s. 79)

Yazar aidiyetle ilgili olarak muhatap olduğu "Rum" mu yoksa "Yunan" mısınız? şeklindeki sorunun Yunanların kültürel kimlik meselesini içinde barındırdığını belirterek bu adlandırmanın tarihçesi ile ilgili uzun analizler yapmaktadır (s. 78-85).

"Notlar ve Çizimlerle Fotoğraflar" (s. 85-167), başlığını taşıyan birinci ek bölümde, büyük bir kısmı tarihi olan 48 fotoğrafa ve Tekirdağ'ın farklı özellikteki tarihi ahşap evlerine ait 18 çizime yer verilmektedir. Bu bölüm okuru görsel ögeler eşliğinde keyifli ve biraz da hüzünlü bir yolculuğa çıkarmaktadır. Yazar her fotoğrafın altında fotoğrafa konu olan yapı, yer veya olayla ilgili uzun ve dikkat çekici açıklamalar yapmaktadır. Birbirinden değerli bu fotoğraflarlardan sadece birine burada yer vereceğiz. Tekirdağ kentinin kozmopolit geçmişine vurgu yapan, (o tarihteki) "Konsolosluklar Sokağı" 9. ve 10. fotoğraflarda (s. 100-101) yer almaktadır. 9. fotoğrafın altında yer alan notta şöyle denilmektedir:

Sokağın bu şekilde adlandııımış olması yüzyılın başlarında Tekirdağ'da bulunan Konsoloslukların sayısı ile açıklanabilir. Şehirde Yunanistan, Ingiltere, Fransa, Avusturya, Almanya, İtalya, Romanya, Rusya, Hollanda, İspanya, Portekiz, Macaristan ve İran konsoloslukları vardı. Konsolosluk sayısının çokluğu şehirdeki ticari hareketliliğe dayanmaktadır. İran Konsolosluğunun varlığı, Tekirdağ'da sayıları çok olan ve belki de İran'da yaşayan soydaşlarıyla ilişkileri olan Ermenilerle izah edilebilir. İtalyan Konsolosluğunun büyük eski ahşap binası günümüzde ayaktadır ve restore edilmiş olup okul olarak kullanılmaktadır. (s. 100) 
Yazarın, farklı konulara ilişkin yazılarının yer aldığı Notlar (s. 169-215) başıklı ikinci ek bölümde dikkatimizi çeken başlıklardan bazıları şöyledir: "İstanbul ve Atina'nın Aşırı Derecede Büyümeleri" (s. 171), "Bu Seyahat Nedir ve Niçin Buradayım?" (s. 172), "Türk Devleti" (s. 173), "Türkiye Gerçeği" (s. 174), "Yunanistan'ın Aşağı Yönlü Seyri" (s. 179), "Yunanistan'da Kimlik Krizi" (s. 192), "Avrupa Birliği Üyesi Olarak Yunanistan" (s. 193), "Şaşırtıcı Türk Ulusu" (s. 196), "Türk Yunan Dostluğu ve Milliyetçi Türkiye Gerçeği" (s. 201), "Kartpostallar (Posta Kartları) ve Taşıdıkları Önem” (s. 203), “Doğu Rumlarının Tarihsel Bellek Konusundaki Çabası" (s. 204), "Osmanlı İmparatorluğunun Orta Sınıfı" (s. 205), “Doğu Trakya'nın 1922 Ekiminde Terk Edilmesi ve Tahliyesi” (s. 205).

Yazar Mavridis, kitabın tekniği ile ilgili olarak okurlara "Son Söz ve Savunma" (s. 217-220) başlığı altında açıklamalarda bulunmaktadır. Kitabın biraz karmaşık bir formata sahip olduğunu kabul eden yazar, neden alışılageldiği üzere akılcı bir sıralama ve anlatım düzeni benimsenmediğini şöyle izah etmektedir:

Seyahatim sırasında ve bunun yazıya dökülmesi sürecinde: kendini tanıma, gelenek (kültürel değerler) ve kimlik sorunlarında zorlu bir görevle karşı karşıyaydım. Böylece sahaya bir yolculuk yaparak, sonunda komplike bir kitaba karar verdim ve kültürel bir gezinti gerçekleştirdim. Burada aslında iki kitap bir arada yer almaktadır. İkinci kitap, anlatısal nitelik taşıyan ilk kitabın içinden ve onun yazım sürecinde ortaya çıkmıştır. Şüphe yok ki böyle bir şey pek alışıldık değildir. (s. 217)

Yazar kitabın yazımında basit olgulardan ve mütevazi deneyimlerden, gerçek duygu ve yaşanmışıklara ve hatta genele uzanmayı olanaklı kılan Yunanların indirgeme metodunun kendisini cezbettiğini belirterek aydınlara ve onları meşgul eden saplantılara karşı olan güvensizliğine rağmen, onların kaleme aldığı ve kendisinin daha önce okuduğu metinlere başvurduğunu belirterek şöyle devam etmektedir:

Bu tür metinler beni: küresel hâkimiyet, kimlik krizi, vatan kavramının anlamı, kutsalın anlamı, mistik olanın anlamı, metafizik kavramı, doğanın kutsanması, mega kentin (kozmo kent) anlamı, [...] Yunanların yalnızlığı, Yunan geleneği, Doğu Rumları, [...], yeniden yaşama dönüş kavramı, kültürleşme, çağdaş Yunan yabancılaşması ve bunlara benzer daha pek çok konu üzerinde düşünce ve anlayışları yazmaya ve yorumlamaya 
yöneltti. Dolayısıyla, pek çoğundan nadiren söz edilse de bunlardan hiçbiri yeni değildir. Ancak kesinlikle günceldir, çünkü gerçeği ve bütünü ele almamıza yardımcı olmaktadırlar. (s. 219)

Kitabın devamında yer alan "Kronolojik Tablo" (s. 221-230) Tekirdağ- Ganos (Işıklar) Dağı- Ganohora bölgesiyle ilgili tarihi olaylara ilişkin olup M.Ö. 6000-4000 yıllarından başlayarak günümüze kadar uzanmakta ve 1980-2000 tarih aralığında son bulmaktadır.

Kitapta yıldızlı [*] dipnotlar çevirmen tarafından (ibrahim KELAĞA AHMET³) verilmiştir. Diğer dipnotlar yazara aittir, ancak kitapta değinilen konularla ilgili ek açıklama gerektiren noktaların "Kaynaklar, Atıflar ve Yorumlar" (s. 231-244) başı̆̆ı altında her bölüm ve alt başlıkla ilgili olarak ayrıntılı bir şekilde verilmesi kitabın bilimsel yönünü güçlendirmektedir. Kitabın sonunda tematik olarak sınıflandırılmış oldukça zengin bir kaynakça (s. 245-254) yer almaktadır.

Sonuç olarak, Dimitris Mavridis'in İstanbul'dan Tekirdağ'a Çağdaş Yunan Kimliğinin Arayışında adlı kitabı Tekirdağ ve tarihi başta olmak üzere ele aldığı konularda bizlere farklı bir bakış açısı kazandırarak önemli bilgiler aktarmaktadır. İlgi duyan okurlara kitabın satışta olmadığını ve Eski Tekirdağ Fotoğrafları Müzesi'nden sağlanabileceğini anımsatırız.

3 Çevirmen: Doç. Dr. İbrahim KELAĞA AHMET, Trakya Üniversitesi, Edebiyat Fakültesi, Balkan Dilleri ve Edebiyatları Bölümü, Çağdaş Yunan Dili ve Edebiyatı Anabilim Dalı 